\title{
MULTI-CRITERIA DECISION MAKING METHODS FOR DETERMINING COMPUTER PREFERENCE INDEX
}

\author{
Maznah Mat Kasim ${ }^{1}$, Haslinda Ibrahim ${ }^{2}$, Mahmoud S. Bataineh ${ }^{3}$ \\ Quantitative Science Program \\ UUM College of Arts and Sciences \\ Universiti Utara Malaysia \\ maznah@uum.edu.my \\ linda@uum.edu.my ${ }^{2}$ \\ mahmoudkt@yahoo.com ${ }^{3}$
}

\begin{abstract}
In helping consumers to make a wise decision in purchasing a personal computer (PC), the use of multi-criteria decision analysis methods is a way to provide ranking of the attributes of PCs and to construct the computer preference index (CPI). This paper employs the Rank Ordered Centroid (ROC) method to do the ranking. The findings reveal that the most important attribute is the CPU, followed by the hard drive, the price, the memory card, the warranty, the size, the screen resolution, the Ethernet, the weight and the DVD. Whilst, the CPI is constructed by using a Multi-Criteria Decision Making (MCDM), called the Simple Additive Weighting (SAW) method. Analysis of data from 25 PCs from four brands, Toshiba, Dell, HP Compaq and Acer, presents the CPI. The resulted CPI shows that two HP Compaq models, Presario V3632 and V3653 are preferred most, while, Acer Aspire 4920-5AA0516MI is the least preferred.
\end{abstract}

Keywords: Attribute, Computer preference index (CPI), Multi-Criteria Decision Making (MCDM), Rank order centroid, Simple additive weighting.

\section{INTRODUCTION}

Making decisions has always been a fundamental activity in everyone's life. Today, purchasing a product such as a personal computer (PC) requires a wise decision from an individual so that he/she would not regret his/her decision. The purchasing criteria directly and significantly affects decision 
making. Various approaches (Norwawi, Ku-Mahamud \& Denis, 2005; Pandian, Nagarajan \& Sazali, 2002) have been developed and adopted to help individuals or organizations to make the best decision. In this work, an attempt has been made to propose quantitative evaluation methods based on multi criteria decision-making (MCDM) methods in considering the quality of the PCs attributes which lead to appropriate purchases. In MCDM problems, the quality attributes for a set of PCs have to be found together with the weights of the attributes that represent their relative importance.

The overall evaluation is obtained by combining both values for each selected $\mathrm{PC}$ to get the final preference ranking. This overall value is also known as index and it can also play the role of an indicator to show trend, direction, or tendency. Besides that, these index values can also guide the decision makers in identifying the best PC, or classifying them into certain groups.

There are many established indices especially in social science research. For example, the United Nations Development Programme had developed the Human Development Index for all countries in the world and it was first introduced in 1990 (Despotis, 2005), The Townsend Index (Lorant, Thomas, Deliego \& Tonglet, 2001) which discusses inequality from a social perspective, and the Malaysia Quality of Life Index (Nik Azman, 2010) were constructed to measure the impact of development projects and programmes on people's well-being.

This paper aims to present the multi-criteria methods for creating the computer preference index (CPI), where Rank Ordered Centroid (ROC) (Barron \& Barrett, 1996) is used to find the weights of the PC's attributes, while the Simple Additive Weighting (SAW) method is applied to combine the weights and the attribute quality of each PC to represent the index values. To the best of the authors' knowledge, the preference index has not yet been constructed to aid in the computer purchase process. The suggested methods could provide the rationale for the PC preference process by considering both, the relative importance and the quality of the attributes.

The rest of the paper is organized as follows: In the next two sections, product attributes and the needed related concepts on MCDM in the sequel are described. Section 4 briefly presents an empirical application of the proposed approaches for university students. The data collection and the methods of ranking are discussed in this section, while the numerical calculations and the results of the case study are presented in section 5. Finally, a comprehensive conclusion is given in the last section. 


\section{PRODUCT ATTRIBUTES}

All products and services can be described in terms of various characteristics or features, which have been technically termed as attributes. The number and types of attributes used by a consumer in making a purchase decision may vary from one product to another. Generally, the number of attributes used in a purchase decision tends to be more for a high-involvement product. Examples of high-involvement products are houses, cars, PCs and machines, while lowinvolvement products include pencils and papers.

In terms of a PC's attributes, most of the time, university students will come up with this kind of list: price, CPU speed, memory (size), hard drive (capacity), screen resolution, Compact Disc read-only memory (CD-ROM), Digital Videodisc or Digital Versatile Disc (DVD), display card, card reader, modem, warranty, Ethernet, video card, weight and size (Lonial, Menezen \& Zaim, 2000; Mc Mullen \& Tarasewich, 2000; Stavins, 1995). However, the choice of the PC's attributes depends on the requirement of a particular student. For example, a computer science student's requirements of a PC are obviously different than that of other students in different fields of study.

\section{MULTI CRITERIA DECISION MAKING}

Multi-Criteria Decision-Making (MCDM) is a decision-making technique that has been applied in various disciplines such as operations research, management, and engineering. Criteria and attributes are used interchangeably and represent various factors or perspectives which become the basis of evaluation of the items considered. The adoption of the MCDM technique helps to enlighten and organize the decision-making process by assisting decision-makers to select the best product based on several criteria (Catalan \& Perez, 2007). A MCDM problem can be easily expressed in a matrix form which is known as the decision matrix. Suppose there are $m$ alternatives or PCs (in this study) to be evaluated under $n$ attributes or criteria. Then, each element in the matrix, $x_{i j}$, represents the quality value of PC $i$ under attribute $j$ for $\mathrm{c}=1, \ldots, \mathrm{m}$ and $\mathrm{j}=1, \ldots, \mathrm{n}$. Finding the composite score for each PC or in other words constructing the index can be solved by the MCDM methods. It is usually done by combining the attributes' weights and the attributes' quality of the alternatives. Many methods are available to derive the weights of the criteria such as the Analytic Hierarchy Process (AHP) (Saaty, 1990), CRITIC (Diakoulaki, Mavrotas \& Papayannalis, 1995), and using expert knowledge (Cheng, 2000). Besides that, there are many MCDM methods that can be applied to do the composition such as Simple Additive 
Weighting (SAW), technique for order preference by similarity to ideal solution (TOPSIS), ELECTRE, and AHP (Triantaphyllou, Shu, Sanchez \& Ray, 1998; Yoon \& Hwang, 1995). The SAW technique has been applied in the Intelligent Learning Environment (ILE) with respect to the performance of the ILE (Kabassi \& Virvou, 2004). The technique has also been used in measuring and comparing the overall competitiveness of Taiwan's five major domestic airlines companies (Chang \& Yeh, 2001).

\section{RESEARCH METHODOLOGY}

This section discusses how the data were collected and the methods used to analyse the data.

\section{Case Study}

A case study was conducted in this study where the data collection was carried out in two phases. In the first phase concerned with the identification of the relevant attributes of a PC, a group of 50 international students who were pursing their post graduate studies in a public university were selected as the respondents. They were given a list of 15 attributes of a PC and they were asked to choose only the ten most important attributes without considering the ranking. In the second phase of the study, questionnaires were distributed to 500 international students and they were required to rank the attributes from the best to the worst. The weights of the attributes were calculated by utilizing the Rank Order Centroid (ROC) method, and the Simple Additive Weighting (SAW) was used to construct the index. Besides that, the normalization of the decision matrix is also crucial to ensure that the data are consistent and coherent. In general, the construction of the CPI can be divided in four main steps; calculation of the attribute weights, normalization of the attribute values, composition of the attribute weights with the attribute values for each PC, and ranking of the PCs based on the composite values.

\section{Rank Order Centroid (ROC)}

Weight refers to the value assigned to an evaluation attribute to indicate its importance relative to the other attributes under consideration. Weights are assigned to the evaluation attribute based on the changes in the range of variation for each evaluation attribute, and the different degrees of importance being attached to these ranges (Kirkwood, 1997). Based on the ROC method, if there are $n$ attributes available, the weight for the attribute ranked in the $i$ th position is, 


$$
w_{i}(R O C)=\frac{1}{n} \sum_{j=i}^{n} \frac{1}{j}
$$

Since a group of respondents is involved in doing the rankings, the average rank method or the average weight method can be used to calculate the final weights. Based on the average rank, rankings given by the respondents for each attribute were averaged out to produce the final ranks and these ranks were used to get the weights by using (1). For the second method, the rankings given by each respondent were used to calculate the weights first by using (1) then, the final weights of the attributes were obtained by finding the averages of those weights. This study employs the second method due to its consistency (Maznah, 2008).

\section{Simple Additive Weighting Method (SAW)}

The SAW method which is also known as the Weighted Linear Combination or the Scoring Method is a simple and the most often used for the multiattribute decision technique. The method is based on weighted average. An evaluation score is calculated for each alternative by multiplying the scaled value given to the alternative of a specific attribute with the weights of the attributes followed by the summing of the products for all the attributes. This sum is called the index and it can be used to evaluate each alternative. The composition is possible after the weights of the criteria are obtained and the data are normalized. The composition gives us a computer preference index (CPI) and is calculated using SAW and it can be written mathematically as follows:

$$
S_{i}=\sum_{j=1}^{n} w_{j} z_{i j}
$$

where,

$S_{i} \quad=$ CPI for computer $i$.

$W_{j} \quad=$ weight of criterion $j, j=1, \ldots, n$.

$Z_{i j} \quad=$ normalized value of PC $i, i=1, \ldots, m$, with respect to criterion $j$ where $z_{i J}=x_{i j} / \max x_{i j}$. After the CPIs, $S_{i}, i=1, \ldots, m$ are calculated, the PCs can be ranked, from the highest index to the lowest index. The PC with the highest index is the recommended PC. 


\section{RESULTS}

Table 1 reveals the ten most important attributes selected by the students in buying PCs. Out of the fifteen attributes listed in the questionnaire, the CDROM, video card, modem, display card, and card reader, were not selected by the students. The computer attributes they considered important to them were the memory card, CPU, hard drive, DVD, warranty, Ethernet, screen resolution, price, size, and weight. The second column shows the number of respondents who chose the attribute in the first column, while the third column shows the final ranking of the attributes based on the number of responses. Based on Table 1, the CPU is ranked as number 1, followed by the hard drive, and the price. However, for the last three attributes, the students choose the Ethernet, weight, and DVD.

Table 1

The Ten Most Important Computer attributes

\begin{tabular}{lcc}
\hline \multicolumn{1}{c}{ Computer attributes } & Responses & Rank \\
\hline CPU & 48 & 1 \\
Hard Drive & 46 & 2 \\
Price & 46 & 3 \\
Memory Card & 45 & 4 \\
Warranty & 42 & 5 \\
Ethernet & 38 & 6 \\
Screen Resolution & 34 & 7 \\
Size & 34 & 8 \\
DVD & 30 & 9 \\
Weight & 28 & 10 \\
\hline
\end{tabular}

In the second phase of the data collection, only 125 questionnaires were successfully completed and returned. Based on the ranking given, the corresponding weights were calculated using (1). Table 2 shows the computed average weights which represent the attributes' weights. The weights are determined by dividing the sum of the weights with the number respondents. For example, the average weight for a CPU is 0.2340 . This is achieved by dividing the sum of the weight, 29.2463, by 125 respondents. If the average weight is bigger, it means that this attribute is more important than the others. Table 3 represents the six attribute values for the 25 available PCs in the 
Varsity Mall of the university in year 2009. The other four attributes were not included because all the chosen PCs had the same information.

Table 2

Attributes'Average Weight and Ranks

\begin{tabular}{lccc}
\hline Attributes & Sum of Weights & Average Weight & Rank \\
\hline CPU & 29.2463 & 0.2340 & 1 \\
Hard Drive & 20.267 & 0.1621 & 2 \\
Price & 19.3569 & 0.1549 & 3 \\
Memory & 15.0461 & 0.1204 & 4 \\
Warranty & 10.5527 & 0.0844 & 5 \\
Size & 7.9197 & 0.0634 & 6 \\
Screen & 6.6965 & 0.0536 & 7 \\
Ethernet & 5.8719 & 0.0470 & 8 \\
Weight & 5.7409 & 0.0459 & 9 \\
DVD & 4.3145 & 0.0345 & 10 \\
\hline
\end{tabular}

Table 3

The Six Attribute Values for the 25 Selected PCs

\begin{tabular}{lcccccc}
\hline Computer & Processor & $\begin{array}{c}\text { Hard } \\
\text { Drive }\end{array}$ & $\begin{array}{c}\text { Price } \\
\text { (RM) }\end{array}$ & Memory & Size & $\begin{array}{c}\text { Weight } \\
(\mathrm{kg})\end{array}$ \\
\hline 1 Toshiba M200-E4112 & 1.66 & 160 & 2599 & 1024 & 3009.37 & 2.26 \\
2 Toshiba L310-A411 & 1.83 & 160 & 2799 & 1024 & 2679.09 & 2.35 \\
3 Toshiba M200-E4314 & 2.1 & 250 & 3799 & 1024 & 3009.37 & 2.20 \\
4 Toshiba M300-E430 & 2.1 & 200 & 3599 & 1024 & 2474.94 & 2.35 \\
5 Toshiba M300-A432 & 2.0 & 160 & 3099 & 1024 & 2474.94 & 2.35 \\
6 Toshiba L310-N401 & 1.83 & 120 & 2399 & 512 & 1761.63 & 2.35 \\
7 Dell Vostro 1310 & 1.8 & 160 & 2299 & 1024 & 3247.61 & 2.9 \\
8 Dell Vostro 1400 & 1.8 & 160 & 2399 & 1024 & 2934.99 & 2.71 \\
9 Dell INSPIRON I1420 & 2.0 & 120 & 2699 & 2048 & 2679.09 & 2.50 \\
$\quad$ [T5750] & & & & & & \\
10 Dell INSPIRON I1420 & 2.1 & 250 & 3999 & 3072 & 2867.90 & 2.60 \\
$\quad$ [T8100] & & & & & & \\
\hline
\end{tabular}

(continued) 


\begin{tabular}{lcccccc}
\hline Computer & Processor & $\begin{array}{c}\text { Hard } \\
\text { Drive }\end{array}$ & $\begin{array}{c}\text { Price } \\
(\mathrm{RM})\end{array}$ & Memory & Size & $\begin{array}{c}\text { Weight } \\
(\mathrm{kg})\end{array}$ \\
\hline 11 Dell INSPIRON 1525 & 2.0 & 120 & 2999 & 2048 & 3452.30 & 2.70 \\
12 Dell INSPIRON 1520 & 2.0 & 160 & 3599 & 2048 & 3168.83 & 2.90 \\
13 Dell XPS M1330 & 2.0 & 250 & 3999 & 2048 & 2573.26 & 2.70 \\
14 HP Compaq Presario & 2.0 & 160 & 2499 & 1024 & 2318.96 & 2.90 \\
$\quad$ B1286TU & & & & & & \\
15 HP Compaq Presario & 2.0 & 160 & 2299 & 1024 & 2318.96 & 1.95 \\
V3839TU & & & & & & \\
16 HP Compaq Presario V3631 & 1.83 & 160 & 2799 & 1024 & 2994.87 & 2.40 \\
17 HP Compaq Presario V3632 & 2.0 & 250 & 2899 & 1024 & 2994.87 & 2.50 \\
18 HP Compaq Presario V3653 & 2.0 & 250 & 3199 & 1024 & 2994.87 & 2.50 \\
19 HP Compaq Presario & 1.83 & 160 & 2499 & 1024 & 2994.87 & 2.50 \\
V3759TU & & & & & & \\
20 HP Compaq Pavilion & 2.0 & 160 & 3999 & 1024 & 2058.11 & 2.20 \\
$\quad$ dv2711TX & & & & & & \\
21 Acer Aspire 2920-6A1G16MI & 2.0 & 160 & 2299 & 1024 & 2847.26 & 2.00 \\
22 Acer Aspire 4920-601G25L & 2.2 & 250 & 2999 & 1024 & 3300.34 & 2.60 \\
23 Acer Aspire 4920-6A1G16L & 2.0 & 160 & 2199 & 1024 & 2847.26 & 2.60 \\
24 Acer Aspire & 1.83 & 160 & 2499 & 512 & 2759.26 & 2.60 \\
4920-5AA0516MI & & & & & & \\
25 Acer Aspire 2920-3A1G16 & 1.83 & 160 & 2799 & 1024 & 2994.87 & 2.50 \\
\hline
\end{tabular}

Based on the attribute weights from Table 2, and the PCs' information in Table 3, the CPIs for the PCs can be constructed. For example, The CPI for Toshiba M200-E4112 is,

$$
\begin{aligned}
S_{\text {Toshiba(M 200-E 4112) }}= & Z_{C P U}\left(\bar{W}_{C P U}\right)+Z_{\text {hard }}\left(\bar{W}_{\text {hard }}\right)+Z_{\text {price }}\left(\bar{W}_{\text {price }}\right)+Z_{\text {memory }} \\
& \left(\bar{W}_{\text {memory }}\right)+Z_{\text {size }}\left(\bar{W}_{\text {size }}\right)+Z_{\text {weight }}\left(\bar{W}_{\text {weight }}\right) \\
= & 0.7905(0.2340)+0.6400(0.1621)+0.3159(0.1549)+1(0.1204)+ \\
& 0(0.0634)+0.0383(0.0459) \\
= & 0.4598 .
\end{aligned}
$$

The normalized attribute values or the $z$ values for Toshiba M200-E4112 had to be computed first before the index could be constructed. For example, the normalized value for Toshiba M200-E4112 hard disk is, $Z_{\text {hard }}=160 / 250=$ 0.64 , since 160 is the hard disk value for Toshiba M200-E4112, and 250 is the 
maximum value for the hard disk attribute. Table 4 indicates the CPI for all PCs where HP Compaq Presario V3632 has been listed in first place, while Acer Aspire 4920-5AA0516MI is at the last position.

Table 4

The CPI and its Rank

\begin{tabular}{clc}
\hline Rank & \multicolumn{1}{c}{ Computer } & CPI \\
\hline 1 & HP Compaq Presario V3632 & 0.5591 \\
2 & HP Compaq Presario V3653 & 0.5475 \\
3 & HP Compaq Presario B1286TU & 0.5410 \\
4 & HP Compaq Presario V3839TU & 0.5401 \\
5 & Dell INSPIRON I1420 [T8100] & 0.5320 \\
6 & Toshiba M200-E4314 & 0.5194 \\
7 & Acer Aspire 4920-601G25L & 0.5165 \\
8 & Toshiba M300-E430 & 0.5035 \\
9 & Dell XPS M1330 & 0.4964 \\
10 & HP Compaq Presario V3759TU & 0.4964 \\
11 & Acer Aspire 2920-6A1G16MI & 0.4923 \\
12 & Acer Aspire 4920-6A1G16L & 0.4869 \\
13 & Toshiba M300-A432 & 0.4868 \\
14 & HP Compaq Presario V3631 & 0.4847 \\
15 & HP Compaq Pavilion dv2711TX & 0.4835 \\
16 & Toshiba L310-A411 & 0.4758 \\
17 & Toshiba M200-E4112 & 0.4598 \\
18 & Dell INSPIRON I1420 [T5750] & 0.4518 \\
19 & Acer Aspire 2920-3A1G16 & 0.4368 \\
20 & Dell INSPIRON 1520 & 0.4276 \\
21 & Toshiba L310-N401 & 0.4253 \\
22 & Dell INSPIRON 1525 & 0.4228 \\
23 & Dell Vostro 1400 & 0.4189 \\
24 & Dell Vostro 1310 & 0.4140 \\
25 & Acer Aspire 4920-5AA0516MI & 0.3948 \\
\hline & & \\
\hline
\end{tabular}




\section{CONCLUSION}

This study employs the MCDM analysis in constructing a CPI for the 25 available PCs in four different brands based on ten selected attributes. The efficient SAW method is used to develop a CPI for these selected PCs, while the ROC method is the key approach for calculating the attributes' weights. Based on the analysis of the results of a real-world problem involving the application of the MCDM for international students in a public university in Malaysia, the following conclusions are drawn. The CPU and the hard disks were considered to be the most important attributes while the DVD attributes were the least important. Four HP branded PCs were the top four most preferred PCs, while three Dell models and the Acer Aspire model 4920-5AA0516MI were the least four preferred PCs. This work hopefully can shed some light on how individuals especially students evaluate and make decisions when they are looking for a PC. Even though the findings cannot be generalized since the analyses are performed on a case study, the empirical results could give some initial idea about the computer purchase behaviour among university students.

\section{REFERENCES}

Barron, F. H., \& Barrett, B. E. (1996). Decision quality using ranked attribute weights. Management Science, 429(11), 1515-523.

Catalan, R., \& Perez, B. (2007). Evaluation of 3D scanners to develop virtual reality applications. Electronics, Robotics and Automotive Mechanics Conference. CERMA 2007, 551-556.

Chang, Y., \& Yeh, C. (2001). Evaluating airline competitiveness using multiattribute decision making. Omega, 29(5), 405-415.

Cheng, S. K. (2000). Development of fuzzy multi criteria decision making support system for municipal solid management. Canada: University of Regina-Saskatchewan.

Despotis, D. K. (2005). Measuring human development via data envelopment analysis: the case of Asia and the Pacific. Omega, 33, 385-390.

Diakoulaki D., Mavrotas G., \& Papayannalis L., (1995). Determining objective weights in multi criteria problem: the critic method. Computer and OR, 22(7), 763-770. 
Kabassi, K., \& Virvou, M. (2004). Personalised adult e-training on computer use based on multiple attribute decision making. Interacting with Computers, 16 (1), 115-132.

Kirkwood, C. (1997). Strategic decision making: multi objective decision analysis with spreadsheets. Belmont: Duxbury Press.

Lonial, S., Menezes, D., \& Zaim, S. (2000). Identifying purchase driving attributes and market segments for PCs using conjoint and cluster analysis. Journal of Economic and Social Research, 2(2), 19-37.

Lorant V., Thomas I., Deliego D., \& Tonglet R. (2001). Deprivation and mortality: An implications of spatial autocorrelation for health resources allocation. Social Science \& Medicine, 53, 1711-1719.

Maznah, M. K. (2008). Determination of criteria weight. Bangi, Selangor, Malaysia: Universiti Kebangsaan Malaysia.

McMullen, P., \& Tarasewich, P. (2000). Selection of notebook personal computers using data envelopment analysis. The Southern Business \& Economic Journal, 23, 200-214

Nik Azman N. A. M. (2010). Malaysia quality of life. Economic Planning Unit, Prime Minister's Department, Malaysia.

Norwawi N. M., Ku-Mahamud K. R., \& Denis S. (2005) Recognition decision making model using temporal data mining technique. Journal of Information and Communication Technology, (4), 37-56.

Pandian, M. V., Nagarajan R., \& Sazali Y., (2002). Decision making using modified s-curve membership function in fuzzy linear programming problem. Journal of Information and Communication Technology (1)1, 1-6.

Saaty, T. L., (1990). Eigenvector and logarithmic least squares. European Journal of Operational Research, 48, 156-160.

Stavins, J. (1995). Model entry and exit in a differentiated-product industry: The personal computer market. Review of Economics and Statistics, 77, 571-584. 
Triantaphyllou, E., Shu, B., Sanchez, S., \& Ray T. (1998). Multi-criteria decision making: An operations research approach. Encyclopedia of Electrical and Electronics Engineering,15, 175-186.

Yoon, K., \& Hwang, C. (1995). Multiple attribute decision making: An introduction. London: Sage Publications. 